\title{
A Transmissão da Psicanálise: Uma Questão de Discurso
}

\author{
Antonio Godino Cabas \\ Universidade Federal do Paraná
}

\begin{abstract}
RESUMO
O presente artigo se propõe a interrogar uma particularidade que envolve o ensino da psicanálise e a formação do psicanalista. Levando em conta que, além de ser uma teoria, a psicanálise é uma prática clínica, o autor observa que este estatuto implica uma série de consequiências. A primeira delas: que a formação de um psicanalista exige uma experiência prática. A segunda: que, de acordo com este principio, o ensino da psicanálise (teoria e doutrina) exige uma didática capaz de ultrapassar os moldes clássicos da comunicação, a informação e o ensino. Daí a importância do conceito de transmissão no que se refere à comunicação do saber e aos modos de proceder do discurso analítico.
\end{abstract}

Palavras-chave: psicanálise; transmissão; formação; ensino.

\begin{abstract}
The Transmission of Psychoanalysis: A Matter of Discourse

The present paper aims to reflect on a unique question which is related to the teaching of psychoanalysis and the formation of a psychoanalyst. As a starting point, it assumes that psychoanalysis is a theory as well as a clinical practice. So, the author observes that it implies into two consequences. The first one is related to the fact that, to become a psychoanalyst, one needs to have clinical experience. The second consequence affirms that psychoanalytical teaching requires a project that might be able to surpass classic ways of communication, information and teaching. Considering these two consequences, the author stresses the importance of the concept of "transmission" as related to the communication of knowledge and to the ways in which psychoanalytic discourse proceeds.
\end{abstract}

Keywords: psychoanalysis; transmission; analytic formation; teaching.

"Um nada de entusiasmo basta para datar um escrito no sentido mais lamentável do termo" escrevia Lacan (1966a, p. 9) referindo-se ao Discurso de Roma no prólogo dos Escritos. Tal parece ser o caso deste texto. Escrito em 1991 como instrumento de um debate, tinha o propósito de intervir no seio de uma polêmica que dominava o panorama da psicanálise de então.

No contexto institucional dos anos 90 a proliferação de grupos de estudos, cursos, e ensinos informais (de forte inspiração universitária) parecia ter resolvido o problema da formação do analista pelo viés dos estudos literários. O presente escrito visava intervir criticamente nesse contexto. Daí seu estilo seco, essencialmente assertivo.

Que - paradoxalmente - vinte anos depois estas ideias tenham sido acolhidas por uma publicação vinculada ao ensino universitário é um fato que merece ser notado... e, a seguir, pensado. No mais, limitei as correções do mesmo ao mínimo necessário para dar a maior evidência à enunciação e suas consequências.

"Que a psicanálise nasceu da ciência é algo manifesto" (Lacan, 1956/1966b, p. 231) diz Lacan. Ao que, em seguida, acrescenta: "que tenha podido surgir em um outro campo é inconcebível” (Lacan, 1956/1966b, p. 231). Mas que esta procedência é fonte de equívocos - diremos nós - é o que há de mais certo. A co- meçar por essa extravagância que consiste em fazer dela uma "teoria pura" para, a seguir, imaginar que é ensinável nos moldes do discurso universitário.

O resultado é que, por esta via, o ensino da psicanálise se transforma em uma questão de magistério e um problema de licenciatura docente. Como se a des- 
coberta freudiana fosse coisa de pensador e o saber da psicanálise uma elaboração voltada para os grandes temas do pensamento. Trata-se de um contexto que supõe - a título de premissa - o abandono da didática. Mais exatamente, disso que na época de Freud recebera o nome de "psicanálise didática". Uma alternativa que nos deixa diante de um dos avatares da formação cujo desfecho já conhecemos. Pois, quando a direção fica entregue à primazia do fantasma, o destino é um beco sem saída ${ }^{1}$.

No fim, é um impasse a cujo respeito só cabe dizer: são os engodos do saber. De um saber à toa... já que é assim que Freud define o tipo de ciência que convém à consciência.

Sabemos, entretanto, que a psicanálise aloja um saber. Por sinal, muito distinto daquele que a ciência realiza. Sobretudo quando observamos que o próprio desta é eliminar o desejo a título de "erro subjetivo". Mas o curioso - o verdadeiramente curioso - se revela quando constatamos que o discurso do analista encontra nesse erro nada menos que o fundamento de sua verdade.

E aí, como não concluir que a didática analítica é a psicanálise didática e não outra coisa?

\section{Da demanda de saber}

A história das instituições analíticas sugere que, para além do reconhecimento dos seus membros, a constituição do grupo atende a uma necessidade real: de como manejar o saber em psicanálise. Algo que comporta seus paradoxos. Em primeiro lugar porque, visto em perspectiva, esse manejo do saber se resume ao manejo da transferência. Em segundo lugar porque Freud foi taxativo. Recomendou aos analistas que escutassem cada caso com total independência dos conhecimentos adquiridos, inclusive, se abstendo de relacionar o caso em curso com outros da sua experiência. Em outras palavras, destacou que a direção da cura concerne o desejo do analista. É a ele - e só ele que compete saber conduzir o trabalho até seu desfecho. Entretanto é aqui, neste ponto, que se revelam os impasses que a extravagância universitária introduz no grupo analítico.

A crença na "teoria pura" e o correspondente pressuposto que ela é ensinável nos termos de uma didática acadêmica induz a uma regressão. Simplesmente, de tratar o desejo como se fosse uma demanda. Demanda de orientação. Demanda de saber. De um saber universal. Sobretudo, um saber sem falhas. É aí que o grupo analítico resvala quando opta por acolher a demanda sem sequer encandi-la e, ainda, lhe propon- do à maneira de resposta o recurso à literatura. Ao saber literário. Como quem apregoasse alto e bom som: sai um prato de letras para a demanda!

A consequência disso não demora em aparecer sob a forma de efeitos bem precisos. $\mathrm{O}$ real que o grupo pretendia atender desaparece sob o imaginário ao qual efetivamente atende. Enquanto isso, o reconhecimento do saber - o notório saber - toma a dianteira e consagra um efeito muito singular. Um efeito a cujo respeito convém lembrar que é de Freud a ideia que o saber, como tal, é uma das formas mais requintadas da resistência à psicanálise (Freud, 1924-1925/1968, p. 73).

\section{Da transmissão}

Por tudo isso, começarei dizendo que - em princípio - a transmissão em psicanálise é transmissão de uma experiência. Entenda-se: analítica. Significa que a pura e simples pergunta pelo sentido da transmissão põe na mesa a função da didática. Isso nos aproxima do âmago da questão.

Afinal, como desconhecer a evidência que todo debate em torno à transmissão concerne à formação do analista? Contudo, há que dizer que é um problema que requer muita prudência. Sobretudo se lembrarmos as palavras com as quais Lacan encerra as jornadas de 1973 sobre a experiência do passe:

Nunca falei de formação analítica, falei de formação do inconsciente. Não há formação analítica. Da análise se depreende uma experiência a qual é completamente errado qualificar de didática. (Lacan, 1975, p. 185)

Sendo assim, convém distinguir ambos os planos dizendo que se a análise é formativa é por quanto supõe a produção de um desejo de saber. Sublinho: desejo e não demanda. Em contrapartida, a transmissão pertence ao campo do testemunho tendo em vista que o que ela põe em jogo não é a reprodução de um saber que passa de mão em mão, mas a transmissão efetiva de um certo real implicado na experiência. Em outras palavras, concerne o tratamento dos impasses que fazem obstáculo ao saber inconsciente.

Vista desta perspectiva, a transmissão põe em causa a presença de um sujeito. A saber: o sujeito freudiano - efeito da realização do inconsciente. E aí, entende-se porque é que Lacan pôde dizer que "na psicanálise, mais do que em qualquer outro lugar, o espírito corre indefectivelmente o risco de descobrir sua medida ao expor seu julgamento" (Lacan, 1956/1966b, p. 239).

A partir daí é fácil entender como e por que a transmissão faz surgir a necessidade de uma formali- 
zação. Como cernir, senão, o real da experiência? Sobretudo, quando é bem próprio do real abrir-se passo através do mal entendido...

Desde cedo, desde o Discurso de Roma, Lacan (1956/1966b) adverte que grande parte dos engodos que entravam o progresso da doutrina estão indissoluvelmente ligados à ambiguidade da língua. Da língua vulgar e seus equívocos. A tal ponto que é fato que a psicanálise pós-freudiana está tão marcada pelas mil e três interpretações dadas aos conceitos fundamentais que evocar a Torre de Babel não é uma ocorrência tão infundada.

Assim, o "retorno a Freud" é o nome de uma necessária retificação da doutrina. Muito mais do que um retorno ao ponto de partida, é um retorno às condições que determinaram o aparecimento das noções freudianas e seus fundamentos. Que estes fundamentos são da ordem do matema e não do inefável é desde já - um postulado de Freud quando demonstra que as articulações do inconsciente se desdobram conforme uma sequência de pensamentos inconscientes logicamente encadeados contestando, assim, a ilusão romântica de um inconsciente pulsativamente criativo e poeta.

\section{Do laço}

De resto, a prática da psicanálise é a prática de um laço. Um laço social. Tal a definição lacaniana do que é um discurso.
Mais que um conceito este princípio é um axioma. Verifica-se sempre e em todos os casos. Seja pelo viés da cura, da análise propriamente dita, da psicanálise pura - a intensão -, seja pelo viés da transmissão e do ensino - a dita extensão - o que está sempre em pauta é um laço. Ele se traduz em uma prática onde o que se apresenta é a função do sujeito na sua relação ao $\mathrm{Ou}-$ tro. Sem alternativas nem meios-termos. A tal ponto que isso se confirma até mesmo nos casos em que o laço termina estruturando-se ao serviço da denegação do discurso analítico. É o que nos ensinam os agrupamentos analíticos quando se revelam organizados em torno à gestão, administração e desfrute de um saber - notório ou não - que funciona como causa final e como meta.

Desta maneira, a questão que se põe é de saber se é possível um modo de transmissão capaz de acolher os ensinamentos do dispositivo analítico. Uma opção que repousa na chance de se forjar uma experiência de ensino congruente com o discurso do analista. Deste discurso diremos que se caracteriza pela primazia de um matema que identifica no objeto o agente do laço e no saber o lugar da verdade. Com o adendo que este saber e, muito particularmente, sua incidência no plano da verdade, determina o lugar do sujeito e, por consequência, o produto da cura.

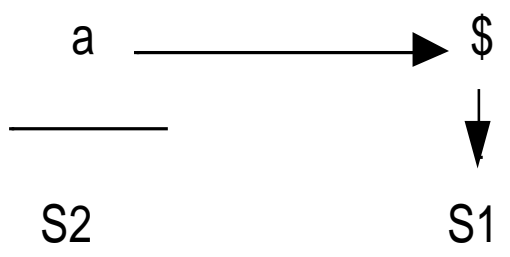

Figura 1. Fórmula de Lacan destinada a representar a lógica interna "do discurso do analista".

Esta aposta - pois a experiência demonstra que se trata de uma escolha - é o derradeiro desafio de toda Escola. Ao pé da letra. Simplesmente por quanto não é garantido, de antemão, que a reunião dos praticantes em nome da psicanálise será de conformidade com o discurso que ela invoca. A prova é que nada impede que uma vez posto a funcionar o laço demonstre operar sobre a vertente do Mestre e do sintoma, da Histérica ou da ciência, e até mesmo do mais estrito academicismo.
Portanto, estamos diante de uma chance que tem margens muito estreitas. Configura o desafio de uma transmissão que se queira digna daquilo que veicula e enuncia: a questão da verdade na experiência do sujeito. Uma chance que necessita "a restauração de um estatuto de ensino idêntico ao da psicanálise didática em sua abertura à ciência" (Lacan, 1966c, p. 236). 


\section{REFERÊNCIAS}

Freud, S. (1968). La resistência al psicoanalisis. Em J. RuizCastillo (Org.), Obras completas (pp. 73-85). Madri: Biblioteca Nueva. (Original publicado em 1924-1925)

Lacan, J. (1966a). Ouverture de ce recueil. Em J. Lacan, Écrits (pp. 9-10). Paris: Éditions du Seuil.

Lacan, J. (1966b). Fonction et champ de la parole et du langage em psychanalyse. Em J. Lacan, Écrits (pp. 237-322). Paris: Éditions du Seuil. (Original publicado em 1956)
Lacan, J. (1966c). Du sujet enfin en question. Em J. Lacan, Écrits (pp. 229-236). Paris: Éditions du Seuil.

Lacan, J. (1975). Sur la passe - Intervention dans la séance de travail sur la passe du samedi 3 novembre 1973. Lettres de l'École Freudienne, 15, 185-193.

Nota:

1 Será necessário lembrar a experiência de Otto Rank e o trágico desfecho da sua singular 'autorização'?

\section{Sobre o autor:}

Antonio Godino Cabas - Psicanalista. Membro da Escola da Coisa Freudiana, Doutor Honoris Causa pela Universidade Federal do Paraná, Doutor em Teoria Psicanalítica pela Universidade Federal do Rio de Janeiro.

Endereço eletrônico: godino@mps.com.br 